\title{
Ultrasound-assisted spinal anesthesia in obese patients
}

\author{
Dermot O'Donnell, MB - Arun Prasad, MBBS · \\ Anahi Perlas, MD
}

Received: 23 June 2009/Accepted: 12 August 2009/Published online: 29 August 2009

(C) Canadian Anesthesiologists' Society 2009

\section{To the Editor,}

We write to share our experience of lumber ultrasonography to assist spinal anesthesia in an obese patient undergoing complex surgery. A 67-yr-old male with a body mass index (BMI) of 44, hypertension, diabetes mellitus and obstructive sleep apnea presented for total hip arthroplasty. Spinal anesthesia was deemed the most appropriate technique after considering the advantages and disadvantages of general versus regional anesthesia and acquiring patient agreement. Marked central obesity and a large umbilical hernia made it very difficult for this patient to achieve the optimal position for spinal anesthesia. Bony landmarks were impalpable on examination, and the landmark-guided approach was abandoned following several unsuccessful attempts at what was believed to be the L2-3 and L3-4 interspaces. With the patient remaining in the sitting position, an ultrasonographic survey of the lumbar spine was performed (Philips HD 11XE ultrasound unit, Philips Medical Systems, Bothwell, WA, USA). To obtain a paramedian longitudinal view, a 2-5 MHz curved transducer was placed vertically $3 \mathrm{~cm}$ lateral to the midline at the level of the base of the sacrum. The sacrum was identified as a white hyperechoic line at a depth of 5-6 cm. The transducer was moved cephalad in this plane, and the ultrasound beam was directed slightly towards midline to obtain the best possible view of the laminae of L5 above the sacrum. The transducer was subsequently positioned to visualize the interspace between the L3 and L4 laminae by counting the laminae from the

D. O’Donnell, MB $(\bowtie) \cdot$ A. Prasad, MBBS .

A. Perlas, MD

Toronto Western Hospital, University Health Network,

Toronto, Canada

e-mail: dod00@hotmail.com sacrum. In this view, the ligamentum flavum-dura mater complex (LF-DM) appeared as double white lines, and the posterior vertebral body (PVB) appeared as a deeper hyperechoic line (Fig. 1: paramedian view). Keeping this interspace in the centre of the ultrasound image where the PVB was best visualized, the transducer was rotated $90^{\circ}$ and then moved towards the midline. In this transverse view, the patient's midline was confirmed with slight cephalad and caudad movement of the transducer revealing the spinous processes of the vertebrae above and below, respectively. The most appropriate interspace for spinal needle passage was determined at the level where the paramedian and midline transverse views provided the best visualization of the LF-DM and the PVB, while the most direct needle trajectory for the dural puncture was taken from the skintransducer angle that provided the best view of the LF-DM and PVB in the transverse plane (Fig. 2: midline transverse view). The built-in sonographic calipers also allowed for estimation of the depth of the LF-DM and PVB. Following skin marking and full aseptic preparation, spinal anesthesia was successfully performed in one attempt using the midline approach at the identified level and the trajectory determined from the transducer angle. Using a 25G, $90 \mathrm{~mm}$ Whitacre ${ }^{\circledR}$ needle (Benlan Inc., Oakville, ON, Canada), 0.5\% isobaric bupivacaine $15 \mathrm{mg}$ plus preservative-free morphine $100 \mu \mathrm{g}$ were administered intrathecally providing complete surgical anesthesia. The patient subsequently underwent total hip arthroplasty uneventfully with minimal sedation.

Obesity (BMI $>30 \mathrm{~kg} \cdot \mathrm{m}^{-2}$ ) and morbid obesity $\left(\mathrm{BMI}>35 \mathrm{~kg} \cdot \mathrm{m}^{-2}\right.$ ) are increasing in the general population with $25 \%$ of the American population in 2007 reported as obese. ${ }^{1}$ The perioperative care of the obese patient is challenging, especially in terms of airway management with a higher risk of failed tracheal intubation as well as the incumbent risks of prolonged ventilation. ${ }^{2}$ 


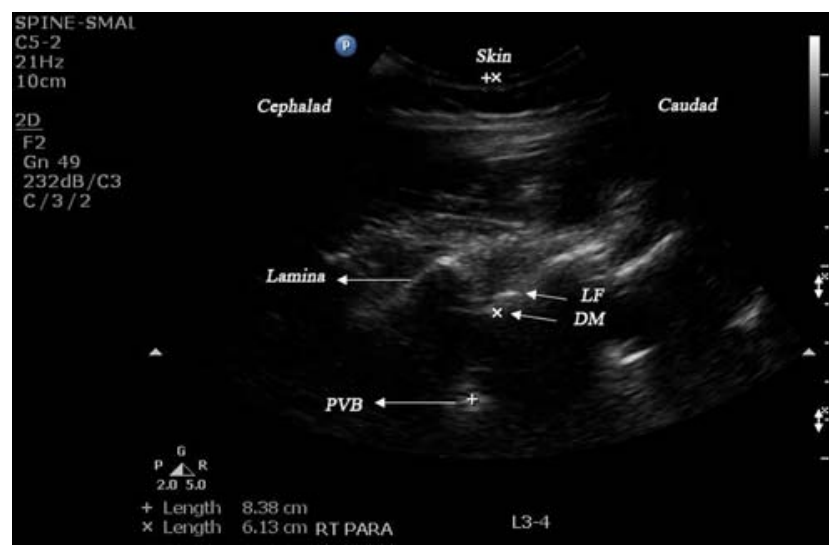

Fig. 1 Paramedian view revealing the posterior vertebral body (PVB) deep to the ligamentum flavum-dura mater complex (LF-DM) between the laminae of the L3 and L4 vertebrae

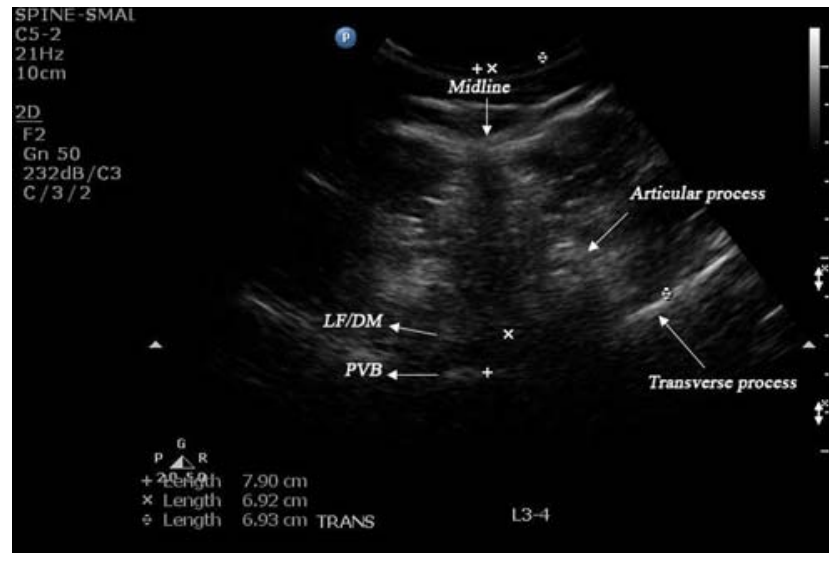

Fig. 2 Midline transverse view revealing the ligamentum flavumdura mater complex at the L3-L4 interspace
Therefore, regional anesthesia, particularly spinal anesthesia, is an attractive option. However, surface landmarks on these patients are often indistinct, making spinal anesthesia technically more difficult. ${ }^{3,4}$ Use of ultrasound has been shown to reduce the number of attempts needed to perform spinal-epidural anesthesia. ${ }^{5}$ Ultrasound imaging of the lumbar spine in this population may assist spinal anesthesia by determining the correct interspinous space, accurately identifying the midline, and estimating the depth of the dura mater. ${ }^{5}$ Systematic ultrasonography using both paramedian and transverse midline planes is therefore a potentially useful aid to spinal anesthesia in the obese patient.

Financial support Department of Anesthesia and Pain Management, Toronto Western Hospital, University Health Network.

Conflicts of interest None declared.

\section{References}

1. US Obesity Trends 1985-2007. Available from: URL:http://www. cdc.gov/nccdphp/dnpa/obesity/trend/maps/. Accessed July 31, 2009.

2. Vallejo MC. Anesthetic management of the morbidly obese parturient. Curr Opin Anaesthesiol 2007; 20: 175-80.

3. Sprung J, Bourke DL, Grass J, et al. Predicting the difficult neuraxial block: a prospective study. Anesth Analg 1999; 89: 384-9.

4. De Filho GR, Gomes HP, da Fonseca MH, Hoffman JC, Pederneiras $S G$, Garcia JH. Predictors of successful neuraxial block: a prospective study. Eur J Anaesthesiol 2002; 19: 447-51.

5. Grau T, Leipold RW, Conradi R, Martin E, Motsch J. Ultrasound imaging facilitates localization of the epidural space during combined spinal and epidural anesthesia. Reg Anesth Pain Med 2001; 26: 64-7. 